\title{
latrogenic uneasiness and fast forward ventricular ectopics
}

A 23-year-old female novice, with no previous history of heart disease was prescribed

1. Cap. amoxycillin $250 \mathrm{mg}, 1$ cap thrice a day

2. A fixed dose combination tablet for cold, 1 tab twice a day, containing:

Pseudoephedrine $60 \mathrm{mg}$

Chlorpheniramine $2 \mathrm{mg}$

Bromhexine $\mathrm{HCl} 8 \mathrm{mg}$

3. Cough syrup 1 teaspoon thrice a day, each $5 \mathrm{ml}$ containing: Ammonium chloride $100 \mathrm{mg}$

Chlorpheniramine $2 \mathrm{mg}$

Menthol $0.5 \mathrm{mg}$ for 7 days, for cold and cough at a private hospital.

On Day 2 the patient returned with complaints of uneasiness, dizziness and weakness. The patient was sent to the author for an opinion. On examination: the pulse rate - 50/ min and highly irregular; temperature - normal; BP - 128/80 mm of Hg; RR - 18/min; not anemic and no pedal edema. Her menstrual history was normal with no missed periods. No member of her family has any known cardiac problem. A detailed history and clinical examination revealed no evidence of any systemic abnormality except the abnormal pulse. An immediate ECG revealed that there were runs of ventricular premature complexes (VPCs). The patient was reassured and advised to stop all medications. She was also instructed to have a cardiology consultation upon worsening of symptoms or any new adverse development. When the patient returned a week later she felt perfectly well. A repeat ECG revealed a marked reduction in the frequency of VPCs. The patient was however advised to have a specialist opinion for the VPCs. The patient could not be seen later but enquiries revealed she was doing fine.

\section{Comment}

The irregular pulse was due to VPCs, which was revealed by the ECG (Figure 1). In VPCs, the pulse is irregular owing to the premature beats. "Frequently repetitive ventricular ectopic activity of a single morphology', as seen in this case, is one form of manifestation of VPCs. ${ }^{1}$

The presenting symptoms on Day 2 could clearly be attributed to pseudoephedrine, since several classes of drugs including sympathomimetics (epinephrine, pseudoephedrine, phenylephrine, phenylpropanolamine, amphetamine), methylxanthines (caffeine, theophylline), digitalis, cocaine and certain general anesthetics (halothane) may induce VPCs. ${ }^{2}$ Since frequent VPCs reduce stroke volume and the cardiac output by the "halving" of the heart rate, symptoms like syn- cope or lightheadedness are a possibility. ${ }^{3}$ In this case the heart rate was $56 /$ min (Figure 1).

Chlorpheniramine (present both in the anti-cold and anticough preparations), an antihistamine with anticholinergic activity also could have contributed to the exaggeration of VPCs, since decreased vagal action is also a well-known destabilizing influence on the existing electrical instability of the heart. ${ }^{4}$

VPCs occur in many healthy individuals. In the absence of heart disease there is little or no increased risk. In patients with disturbing or disabling palpitations due to VPCs, avoidance of potentially aggravating factors (e.g. tobacco, coffee, caffeine-containing beverages, environmental stress or stimulants) should be tried before pharmacologic therapy. ${ }^{2,5}$ In the present case the aggravating factors were clearly the drugs (mainly pseudoephedrine and may be to a lesser extent chlorpheniramine). As mentioned earlier, all the drugs were stopped and the patient was relieved of the disturbing symptoms. There was a marked reduction in the frequency of VPCs (Figure 2). The patient was advised against use of cough and cold remedies on her own. She was also advised to alert the physician in future about her condition .

The syndrome of right bundle branch block, S-T segment elevation in the anterior precordial leads, and risk of sudden death has been described in the literature. Such cases have no associated structural heart disease and in some, the patients are asymptomatic. It is commonest in young adult males and has been suggested as the basis for the so-called "sleep death" in young Asian males. ${ }^{5}$ Since the patient is a young

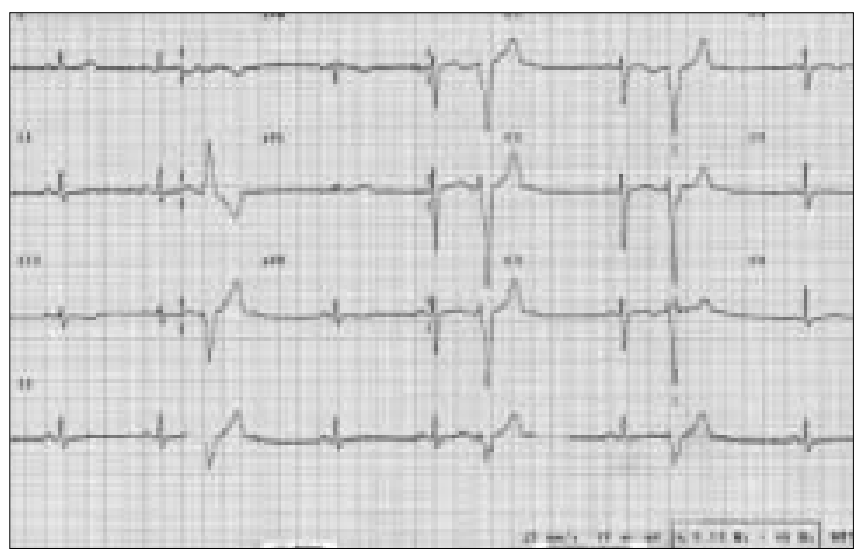

Figure 1: ECG revealing runs of VPCs while the patient was on anti cold medication 


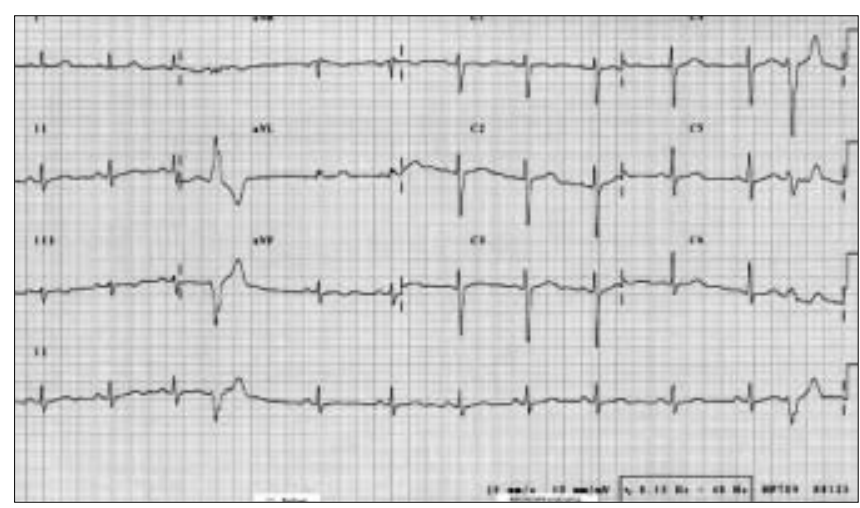

Figure 2: ECG taken one week after stopping the anticold medication

Asian female, she was advised for a specialist opinion of her condition.

\section{Lessons}

1. Examination of the pulse: It is to be emphasized that many a times pulse examination is not given due consideration (leave alone examining the same for one minute) and the chances are that such cases could be easily missed. Consequently, appropriate and timely intervention is also unlikely, leading to unnecessary confusion for the caregiver and protracted suffering for the patient. Caution may be exercised if a prescription of sympathomimetic drug is contemplated if one encounters an abnormal pulse.

2. Importance of medication history: In many instances practitioners also fail to elicit the medication history. A constellation of signs and symptoms with which a patient presents need not always be due to the disease, but may be $\operatorname{drug}(\mathrm{s})$-induced.

3. De-challenge: The majority of the drug-induced adverse effects are likely to disappear once the offending drug is stopped (de-challenge). Embarking upon a rigorous and more specific approach may be necessary only if the condition warrants. It is a general tendency to treat with one or more other drugs, to ward off a new complaint, which may be a potential invitation for further complication.

4. Appropriate warning and advice to the patient: If an adverse effect is suspected to be due to a drug, the proof lies in its disappearance on stoppage (de-challenge) and appearance on reintroduction (re-challenge) of the same. In many instances re-challenge may not be possible due to ethical reasons, even if the condition is trivial. But an inadvertent re-challenge can be avoided by appropriate warning to the patient regarding the future use of such drugs.

5. Message: This is a case of exaggeration of otherwise harmless preexisting VPCs by a commonly used OTC product (pseudoephedrine), presenting atypically (as uneasiness, dizziness). The message is loud and clear: "please prescribe rationally; not routinely".

\section{G. Sivagnanam}

Department of Pharmacology, Chengalpattu Medical College, Chengalpattu - 603001, India. E-mail: drsivagnanam@hotmail.com

\section{References}

1. Camm AJ. Cardiovascular Disease. In: Kumar, Clark, editors. Clinical Medicine. 5th ed. Edinburgh: Saunders; 2002. p. 701-832.

2. Pompilo FM, Gill M. Cardiac arrhythmias. In: Textbook of Therapeutics: Drug and Disease Management. 6th ed. Baltimore: Williams and Wilkins; 1996. p. 763-810.

3. Josephson ME, Zimetbaum P. The Tachyarrhythmias. In: Harrison, editor. Principles of Internal Medicine. 15th ed. New York: Mc Graw-Hill; 2001. p. 1292308.

4. Singh BN. Overview of antiarrhythmic drug therapy. In: Cardiovascular Pharmacology and Drug Therapy. 1st ed. New York: Churchill Livingstone: 1994. p. 617-43.

5. Myerburg RJ, Kloosterman EM, Castellenos A. Recognition, clinical assessment and management of arrhythmias and conduction disturbances. In: Hurst, editor. The Heart. 10th ed. New York: Mc Graw-Hill: 2001. p. 797-874.

\title{
FIRST ASIA PACIFIC CONFERENCE OF SEXOLOGY (UNDER THE PATRONAGE OF ASIAN FEDERATION FOR SEXOLOGY)
}

\author{
The Taj Mahal Hotel, Bombay (Mumbai) India, \\ November 21 - 24, 2004 \\ Theme: "Sexuality in the Changing World".
}

For more details please contact:

Prof. Prakash Kothari

203-A Sukh Sagar, N.S. Patkar Marg, Mumbai - 400007. India.

E-mail: drpkothari@hotmail.com • Website: www.fapcs.com 